\title{
Investigation about Teachers' and Managers' View about Annual Evaluation System of Teachers' Performance in Iran
}

\author{
Fereidoon Yazdani \\ Payam-e-Noor University, Malayer, Iran \\ Email: f.yazdani@yahoo.com
}

Received 20 June 2015; accepted 7 August 2015; published 10 August 2015

Copyright (C) 2015 by author and Scientific Research Publishing Inc.

This work is licensed under the Creative Commons Attribution International License (CC BY).

http://creativecommons.org/licenses/by/4.0/

(c) (†) Open Access

\section{Abstract}

This research was carrying out with purpose of investigation about teachers' and managers' view about annual evaluation system of teachers' performance. The research method was descriptive (survey research) and statistical population included all elementary teachers and managers in Malayer. The total numbers of teachers were 3050 and mangers were 301 . For sampling, a biased method was used. So, $\mathbf{1 7 0}$ managers and 380 teachers were selected. The instrument was two research-made questionnaires. For validating of questionnaires, the content and formal validity was used. So, the specialists' appraisal was applied. Also for making questionnaire reliable the Coronach's alpha was used. So, alpha coefficient for managers' and teachers' questionnaire respectively was: 0.96 and 0.87 . However, the result shows that from manager's view the annual evaluation system of teachers' performance is appropriate, but that from teachers' view it isn't good. Also another result shows that, there are significant differences between teachers' and managers' view about quality of annual evaluation system of teachers' performance, in totally and in all domains (instructional domain, discipline domain, good humanity relationship, cooperation of teachers, scientific researches of teachers, and job motivation of teachers).

\section{Keywords}

Performance Evaluation, Annual Teachers' Performances, Managers' Attitude, Teachers' Attitude, Elementary Schools of Malayer

\section{Introduction}

Evaluation of human resources is the most sensitive issues in administrative affairs. Meanwhile, the most complicated evaluation is evaluation of teacher's activities. The reason of the complexity is low validity and impre-

How to cite this paper: Yazdani, F. (2015). Investigation about Teachers' and Managers' View about Annual Evaluation System of Teachers' Performance in Iran. Creative Education, 6, 1523-1529. 
cision in methods and instruments of assessment and measurement in this kind of evaluation, because none of this method and the instrument can't give accurate data (Seif, 2010). Due to different comprehensions from performance evaluation concept, there is contradictory view about this issue. Therefore, for somebody evaluation has a horrid face that can frustrate their independence. Meanwhile, there are another people that have mindful views about performance evaluation and believe that it is a useful tool for assessing and judging the performance of employees in order to become skilled and professional workers (Council of Australasian Tribunals Inc., 2007).

\section{Statement of the Problem}

The results of researches showed that human powers don't accept all results of their performance evaluations. They are interest to give their proposals and ideas to evaluators and decision makers (Ikan, quoted in Ahanchian, 2003). Also researches showed that individual's satisfaction and comprehension from evaluation processes can bring about more generative behavior in them and restrain misconceptions of people, because these misconceptions can disturb organizational unity.

Until now, few researches have been performed about workers' performance of administrative organizations. For example Ebili (2001) in a study by the name of "appraisal of current evaluation plan of government workers" maintain that about $70 \%$ of workers believe that this plan isn't relevant with administrative realities of the country (year of 2001). Also nearly the fifty percent of subjects believed that there are serious obstacles and damages (such as: not operability of instructions, low submission of responsibilities, no transparency of criteria and so on) in implementation of evaluation system of workers.

There is another research that investigates sub-elements of teachers' evaluation systems. e.g. Ahanchian (2003) showed that evaluators' gender hasn't a significant role in score that evaluators give to the individuals. Vice versa, some research in many countries such as: Franc, USA, and UK, has showed that individuals' gender has a significant effect upon their value judgments (Berkowitze, 1993). However, there are some researches that are related to evaluation of faculty members of university from student's point of view. For instance research of Karam Doost (2004) and Seif (1991) are this kind of study. But about teachers' idea or their views about performance evaluation system until now any research don't performed.

Education apparatus include various components such as: teachers, students, curriculum, instructive and executive workers, and so on. It is obvious that educational systems' successfulness is depending to optimum activity of the mentioned components in together. So, evaluation of teachers' performance has prominent impotence in respect to the others components. Teachers are in hearth of any progress in any educational systems. $\mathrm{He} / \mathrm{she}$ is the most important and the most effective factors in student's academic achievement. In recent years it approved that teachers are the most important factor in schools' progress. Recently, due to growth of responsibility (liable) revelation, evaluation of the teachers has become an important issue over the world (Strong \& Ostrander, 2006).

Anyway, beyond the importance of teachers' performance evaluation, there are many issues about this subject. E.g. we must investigate that to what extent current evaluation of the teachers is accordance with real and correct criteria; and investigate to what extent these evaluations are satisfied the stakeholders. Of course, until now some research has performed about these issues but the magnitudes of them wasn't enough?

Anyway, in this study, researcher intend to investigate differentiations between elementary teachers and managers' point of view about annual system of teachers' performance evaluation in elementary schools of Malayer city, in Hamadan province. The implementation of this research has frequently important. In the first place, results of the study can identify the gap between views of two group (teaches and managers). These results identify differences between the attitudes of them for decision makers. The authorities can use form this finding for recognizing of deficiencies and differences in perceptions and attitudes of two group (teachers and managers). The differences between the perceptions of the teachers and managers can bring about the frustration of evaluation aims. by getting of this recognition we can better planning for omitting of obstacles. In second place, the study can open a new window in front of the future researchers. As we know, a good study must be heuristic. This mean that a good study must be bring about to new inquiry questions and new hypothesis. On the other hand, it hope that this study help to widening of knowledge boundaries.

\section{Literature Review}

An investigation upon evaluation literature showed that study about evaluators’ and teachers’ view (as subjects 
in studies) didn’t noticed by researchers. Anyway, in a few studies the individuals' attitudes were investigated. In the following some studies is introduced:

Frokhi (2001) has investigated the elementary teachers of Neishaboor city of Iran about methods of clinical supervision and comparing the results of it with desired status. The results of his study revealed that from subjects' view, the clinical supervisors have largely used form direct methods and their supervisor actions of the supervisor aren't efficient. Another results of Frokhi (2001) showed that the supervisors with a high job background used effective methods than supervisor with low job background.

Keikhaee, Novidian, Tabasi and Sargazi (2002) have studied the faculty members of medical sciences of Zahedan city about faculty evaluation procedures. the findings of their study revealed that in views of faculty, students does complete the evaluation forms of professors with personal prejudice (57/9\%), or with no honesty (86/6\%) or with Indifference (89/1\%). also faculty believed that about $20 \%$ of actions evaluate with some criteria as: students' views, research activities, self-assessments, group directors, colleagues' views, and educational ministry.

Karam Doost (2004) in a study showed that there is a significant correlation between the students' academic achievement scores and scores of faculties' evaluation.

Fatahi, Ndhami, Noohi, Nakhaee, and Islami Nejad (2005) have studied the faculty members of medical sciences of Kerman city about methods of professors' evaluation. Their findings showed that in general the majority of professors have agreed view with evaluation principle. But they have proposed that in the evaluation processes, evaluators must be using multiple methods, apply accurate criteria, implement fine procedures, and use secret feedback.

Sarchami and Salmanzadeh (2004) have investigated the faculty members' and group directors' view about effectiveness of evaluation methods of professors' performances based on students' view, upon the changing the professors' performance at the Iran medical sciences. Their findings showed that all subjects (faculty and group directors) believed that these kinds of evaluation methods are low effective affect upon professors' performance. Also there was a significant difference between faculty member' view and group directors' view about festivenesses of these approaches.

Tootoonchi, Changiz, Ali Pour, and Yamani (2005) have studied the faculty members of medical sciences of Isfahan city about faculty evaluation process and have showed that the professors have a negative opinion about the executive procedures of professors' evaluation and also in respect to the evaluation forms.

Ali Shiri, Azad Marzabadi, Hoseini, Fojorak, and Noori (2013) have compared the faculty members' view with students' view about evaluation forms for theoretical courses. Their results showed that all subjects (students and faculty) want that evaluation forms be changed correctly.

One study that implemented in region of Gasnik and Peng Tank in Taiwan with the name of: "an investigating about status quo of educational supervision in high schools of Taiwan with style of school-based evaluation" by the Taiwanese researchers. The results of the study showed that:

The majority of teachers have positive opinion about educational supervision with style of school-based evaluation

There was a significant and positive correlation between ages, job background, sex, with positive opinion about educational supervision about style of school-based evaluation.

The supervision with style of school-based evaluation is better accepted in the male than female.

The school principal and teachers were satisfied by style of school-based evaluation.

the workers that works in the small school has more positive opinion than those who works in large school in respect to style of school-based evaluation.

Those supervisors that have high academic graduation level and with more scientific qualification get better acceptance among the school managers and teachers (quoted in Hasn Pour, 2006).

\section{Research Method}

The research method was descriptive (survey research) and statistical population included all elementary teachers and managers in Malayer. The total numbers of teachers were 3050 and mangers were 301. For sampling, a biased method was used. So, 170 managers and 380 teachers were selected based on the Krejcie and Morgan' table of sampling (1970). Prior to data collection the consent participants was informed. The instrument was two research-made questionnaires, one for school managers and other for teachers. This questionnaire was made 
based on the six dimensions (instructional behaviors, discipline in the teachers' actions, appropriate human communication, cooperation and team working, scientific activities, job motivation and interest). for assessing the these six dimensions, 28 statements (item) was write, 6 item for assessing the instructional behavior dimension, 5 item for assessing the discipline in the teachers' actions, 5 item for assessing the appropriate human communication, 4 item for assessing the cooperation and team working, 5 item for assessing the scientific activities, and finally 3 item for assessing job motivation and interest. the statements (items) in any forms of questionnaires was similar but was different. For validating of questionnaires, the content and formal validity was used. So, the specialists' appraisal was applied. Also for making questionnaire reliable the Coronach's alpha was used. So, alpha coefficient for managers' and teachers' questionnaire respectively was: 0.96 and 0.87 . Data were analyzed by SPSS software (16. Copy). Also, for data analysis the descriptive statistics (such as: central tendency) and inferior statistics (such as: Kolmogrov-Smirnov \& one-sample t-test, Mann-Whitney U and so on) was used.

\section{Findings}

\subsection{Descriptive Analysis}

\section{Demographic Features of Participants}

For getting a summary from demographic features of participants the descriptive analysis was used. See Table 1.

As Table 1 showed the approximately 70 percent of participants were teachers and only about 30 percent of participants were managers.

\subsection{Inferential Analyses}

\subsubsection{The First Question}

What is the opinion of school managers about teachers' annual performance evaluation system?

Before the responding to this question we must investigating the status of data distribution, see Table 2.

As Table 2 showed the output of Kolmogrov-Smirnov test isn't significant $(p>0.05)$. This suggests that the data distribution is normal. So, now we can use from parametric statistics. See Table 3.

As Table 3 showed, the $P$ value: 0.01 with a t value: 15.92, and with a df: 169 , in a two-tailed test is significant. So on the basis of this finding we can say the school managers' opinion about teachers' annual performance evaluation system is good and in an optimum level.

Table 1. Resultas of analysis upon the demographic features of participants.

\begin{tabular}{cccc}
\hline Subjects & Frequency & Percent & Cumulative percent \\
\hline Managers & 170 & 31 & 31 \\
Teachers & 380 & 69 & 100.0 \\
Sum & 550 & 100.0 & \\
\hline
\end{tabular}

Table 2. The Kolmogrov-Smirnov test related to managers' view.

\begin{tabular}{ccc}
\hline $\mathrm{N}$ & Kolmogrov-Smirnov & Significant level \\
\hline 170 & $0 / 86$ & $0 / 45$ \\
\hline
\end{tabular}

Table 3. Results of one-sample t-test for analyzing the data that relate to school manager' view.

\begin{tabular}{|c|c|c|c|c|c|c|}
\hline & \multicolumn{6}{|c|}{ Test Value $=3$} \\
\hline & \multirow{2}{*}{$\mathrm{t}$} & \multirow{2}{*}{ df } & \multirow{2}{*}{$\begin{array}{l}\text { Sig. } \\
\text { (2-tailed) }\end{array}$} & \multirow{2}{*}{$\begin{array}{c}\text { Mean } \\
\text { difference }\end{array}$} & \multicolumn{2}{|c|}{$95 \%$ confidence interval of the difference } \\
\hline & & & & & Lower & Upper \\
\hline $\begin{array}{l}\text { Views of school managers about teachers' } \\
\text { annual performance evaluation system }\end{array}$ & 15.92 & 169 & 0.000 & 1.21 & 1.05 & 1.36 \\
\hline
\end{tabular}




\subsubsection{The Second Question}

What is the opinion of elementary teachers about herself annual performance evaluation system?

Before the responding to this question we must investigating the status of data distribution, see Table 4 .

As Table 4 showed the output of Kolmogrov-Smirnov test is significant $(p<0.05)$. This suggests that the data distribution isn't normal. So, now we must be use from non-parametric statistics. See Table 5.

As Table 5 showed, the P value: 0.19 with a chi-square value: 1.69 , and with a df: 1 , in a two-tailed test isn't significant. So on the basis of this finding we can say the elementary teachers' opinion about their annual performance evaluation system isn't good and there is a gap between the status-quo of their opinion with optimum level.

\subsubsection{The Third Question}

Is there any differences between school managers' and elementary teachers' view about annual performance evaluation system?

As we see in Table 3, the data distribution in the data relate to teachers wasn't normal, so we must be use from non-parametric statistics for responding to third question. First see Table 6.

As we see in the table of 6 there is a prominent difference between mean rank of mangers and teachers' scores but do these differences is meaningful from statistical side? See Table 7.

As we see in Table 7 there is a significant difference between mean rank of mangers and teachers scores, because: $p<0,05, \mathrm{~N} 1=170, \mathrm{~N} 2=380, \mathrm{U}=316$. So with respect to Table $5 \&$ Table 6 we can say there is a

Table 4. Kolmogrov-Smirnov test that relate to elementary teachers' view.

\begin{tabular}{ccc}
\hline $\mathbf{N}$ & Kolmogrov-Smirnov & Significant level \\
\hline 380 & $1 / 92$ & $0 / 001$ \\
\hline
\end{tabular}

Table 5. Results of Chi-Square test for analyzing the data that relate to elementary teachers' view.

\begin{tabular}{cc}
\hline & Level \\
\hline Chi-Square & $1.688 \mathrm{a}$ \\
$\mathrm{df}$ & 1 \\
Asymp. Sig. & 0.194 \\
\hline
\end{tabular}

Table 6. A comparing between the ranks of scores of teachers' and managers' view.

\begin{tabular}{ccccc}
\hline & Variable (post) & N & Mean rank & Sum of ranks \\
\hline \multirow{3}{*}{ View } & Managers & 170 & 129.81 & 4024 \\
& Teachers & 380 & 65.05 & 8066 \\
& Total & 550 & & \\
\hline
\end{tabular}

Table 7. Results of Mann-Whitney U test for comparing the views of teachers and managers.

\begin{tabular}{cc}
\hline & Views of teachers and managers \\
\hline Mann-Whitney U & 316 \\
Wilcoxon W & 8066 \\
Z & -7.19 \\
Asymp. Sig. (2-tailed) & 0.000 \\
\hline
\end{tabular}


significant differences between school managers' and elementary teachers' view about annual performance evaluation system. Also we can say the views of school manager were more optimistic than elementary teachers.

\section{Discussion and Conclusion}

\subsection{The First Finding}

One of the main findings of this research was that from school managers' point of view the teachers' annual performance evaluation system is in an appropriate status. As pervious researches haven't studied this issue there isn't possibility for comparing this findings with literature. But from one side, perhaps we can compare this finding with Ebili's research. Ebili (2001) in a study maintains that about $70 \%$ of workers believe that current evaluation plan of government workers isn't relevant in respect to administrative realities of the country (year of 2001). Also nearly the fifty percent of subjects believed that there are serious obstacles and damages (such as: not operability of instructions, low submission of responsibilities, no transparency of criteria and so on) in implementation of evaluation system of workers.

Anyway the managers look at to this system from a responsible post or duty, so, their responses can be somewhat biased or with prejudice. So, it can be more obvious that this controversy in results of different studies is natural.

\subsection{The Second Finding}

Another result of this study was that from elementary teachers' view the annual performance evaluation system isn't in the appropriate status. As pervious researches haven't studied this issue there isn't possibility for comparing this findings with literature. But from one side, perhaps we can compare this finding with Tootoonchi et al. research. Tootoonchi and associate (2006) revealed that the professors have a negative opinion about the executive procedures of professors' evaluation and also in respect to the evaluation forms. So, the second finding of the study is consistent with Tootoonchi et al. result.

So this finding revealed that form elementary teachers' view the annual performance evaluation system has some deficiencies and needed to new reforms.

\subsection{The Third Finding}

The third result of study revealed that there is a significant differences between school managers' and elementary teachers' view about annual performance evaluation system. Also we can say the views of school manager were more optimistic than elementary teachers. As pervious researches haven't studied this issue there isn't possibility for comparing this findings with literature.

In explaining of this result we must note to the professional responsibility of the two groups of responders. So, from this perspective we can see that managers that try to be conservatism. They have some professional duty, so they have responded to the questionnaire with a little prudence. But the teachers respond can be more near to reality. So, for conclusion from data we must be cautiousness. Anyway the responses of the teachers is accompany with honesty.

\section{Applied Recommendations}

1) It recommends to the educational authority that performs a review upon teachers' annual performance evaluation system and reforms weak points of it.

2) It recommends that educational authority organizes a workshop for school mangers in the subjects of importance of teachers' evaluation performance.

3) It proposes to the educational authority that omits the deficiencies and reinforces the strong points of teachers’ performance evaluation system.

\section{Funding}

This article is an adoption from a research that is implemented by the financial resources of Payam-e-Noor University, Hamadan province. 


\section{References}

Ahanchian, M. R. (2003). The Effect of Having or Not Having the Same Gender upon the Results of Evaluations of Professors from Students, View. The Magazine of Psychology and Educational Sciences, 33, 183-199.

Ali Shiri, Gh., Azad Marzabadi, E., Hoseini, S. M., Fojorak, H., \& Noori, R. (2013). Comparing the Faculty Members’ View with Students' View about Evaluation Forms in Theoretical Courses. Educational Strategies in Medical Sciences, 6, 135139.

Berkowitze (1993). Social Psychology. Tehran: Asatir. [In Persian]

Council of Australasian Tribunals Inc. (2007). Should Tribunals Be Required to Meet Performance Criteria and, If How Would They Be Defined and Enforced. Australia: Council of Australasian Tribunals Inc. http://www.coat.gov.au/docs/QLDChapter/seminar_14-2-03_performance_criteria

Ebili, K. (2001). Evaluating the Current Design of Government Workers. The Magazine of Psychology and Educational Sciences, 6, 91-103.

Fatahi, Z., Adhami, A., Noohi, E., Nakhaee, N., \& Islami Nejad, T. (2005). Investigation about the Faculty Members of Medical Sciences of Kerman City about Methods of Professors' Evaluation in Academic Years of 2002-2003. The Medical Magazine of Hormozgan, 9, 59-66.

Frokhi (2001). Investigating the Elementary Teachers of Neishaboor City of Iran about Methods of Clinical Supervision and Comparing the Results of It with Desired Status. M.A. Thesis in Educational Management, Tehran: Educational Sciences College, University of Tehran.

Hasn Pour (2006). Investigation about Supervision Style Educational Guidance Mans in Rural and Towny Schools of Azarbaijan-e-Sharghi Province in Academic Years of 1999-2000. M.A. Thesis in Education, Tabriz: Islamic Azad University, Branch of Tabriz Province.

Karam Doost, N. A. (2004). An Investigation about Relation between Students' Academic Achievement Scores and Scores of Faculties' Evaluation at the Psychological and Educational Sciences College, in Academic Years of 1998-1999 \& 20002001. The Magazine of Psychological and Educational Sciences, 34, 57-76.

Keikhaee, A. A., Novidian, A., Tabasi, M. A., \& Sargazi, G. H. (2002). The Opinions of Faculty Members of Medical Sciences of Zahedan City about Faculty Evaluation Procedures. Tbibe Shargh Magazine, 4, 135-140.

Krejcie R. V., \& Morgan, D. W. (1970). Determining Sample Size for Research Activities. Educational and Psychological Measurement, 30, 602-690.

Sarchami, R., \& Salmanzadeh, H. (2004). Faculty Members’ View about Effectiveness of Methods of Evaluation of Professors' Performances Based on Students' View upon Changing the Professors Performance at the Iran Medical Sciences. The Scientific Magazine of medical Sciences University and Health Services in Ghazvin City, 34, 69-71.

Seif, A. (2010). Educational Measurement, Assessment and Evaluation. Tehran: Doran.

Sesif, A. (1991). Evaluation of Professor Based on the Students’ View: To What Extent We Can Rely on It? Psychological Research, 1, 12-24.

Strong, J. H., \& Ostrander, L. P. (2006). Client Surveys in Teacher Evaluation. In J. H. Strong (Ed.), Evaluation Teaching (2nd ed.). Thousand Oaks, CA: Crown Press. http://dx.doi.org/10.4135/9781412990202.d41

Tootoonchi, M., Changiz, T., AliPour, L., \& Yamani, N. (2005). The Views of Faculty Members of Medical Sciences of Isfahan City about Process of Professor Evaluation. The Iranian Magazine of Education in Medical Sciences, 6, 22-28. 